\title{
Photoredox/Nickel Dual-Catalyzed Reductive Cross Coupling of Aryl Halides Using an Organic Reducing Agent
}

\author{
Abhishek Dewanji, ${ }^{\dagger}$ Raoul F. Bülow ${ }^{\dagger}$ and Magnus Rueping $*, \dagger, \ddagger$ \\ $\dagger$ Institute of Organic Chemistry, RWTH Aachen University, Landoltweg 1, 52074 Aachen, Germany. \\ $\$$ King Abdullah University of Science and Technology (KAUST), KAUST Catalysis Center (KCC), Thuwal 23955-6900, \\ Saudi Arabia.
}

KEYWORDS: Reductive coupling, Metallaphotoredox, Organic reductant, Perfluoroarene, Biaryl

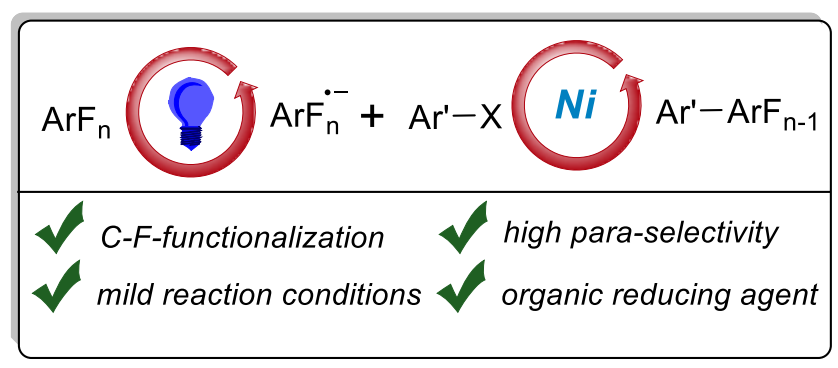

\begin{abstract}
A successful protocol for the reductive aryl-aryl cross-coupling of polyfluorinated arenes with a broad range of aryl halides has been developed. Sequential carbon-fluorine bond cleavage and carbon-carbon bond formation are two of the important features of the reaction. Addition of an aryl radical anion to a nickel intermediate was achieved for the first time using polyfluoroarenes as radical precursors. This, in combination with the excellent para-selectivity, paves the way for the synthesis of various new multifluorinated biaryl compounds.
\end{abstract}

The combination of visible light with transition metal-catalysis has recently paved the way to more elaborated transformations. ${ }^{1}$ The photoredox cycle serves as a milder alternative for an oxidant or reductant, ${ }^{2,1 g}$ as an energy-transfer-agent, ${ }^{3}$ or it directly intercepts the transition metal catalytic cycle. ${ }^{4}$ In the latter case, a free radical species, generated by the photoredox cycle, reacts with an in situ formed organometallic intermediate to furnish a new organometallic species (Scheme 1). This single-electron step provides either improved reactivity or an alternative to the traditional two-electron steps of transition metal-catalysis.

Nickel salts are among the most versatile metal catalysts applied in the field of metallaphotoredox chemistry, being employed in various $C-C^{3 c, d, 4,6}$ and $C-X\left(X=\right.$ heteroatom $^{2 \mathrm{~d}, 3 b, 3 e, 5}$ bond formation reactions. Regarding the $\mathrm{C}-\mathrm{C}$ bond formation reactions, these have been mainly limited to $\mathrm{C}\left(\mathrm{sp}^{3}\right)$ $\mathrm{C}\left(\mathrm{sp}^{3} / \mathrm{sp}^{2} / \mathrm{sp}\right)$ variants with a few exceptions involving acyl radicals. ${ }^{6}$ This is because the photochemically generated free radical has almost always been a $\mathrm{C}\left(\mathrm{sp}^{3}\right)$-centered radical. From a mechanistic point of view, generating and handling $\mathrm{C}\left(\mathrm{sp}^{2}\right)$ centered aryl and vinyl radicals is more difficult, as these radicals are less stable and often cause undesired side reactions leading to an inefficient catalytic cycle. ${ }^{7}$ This problem does not arise in the case of alkyl and acyl radicals, as they are more stabilized compared to the aryl and vinyl radicals.

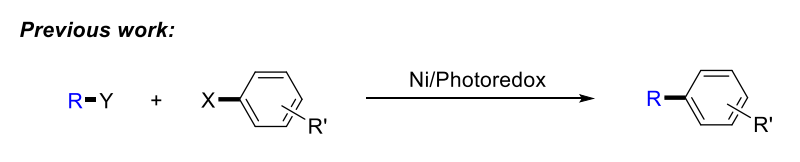

When $\mathbf{R} \cdot$ is a $\mathbf{C}\left(\mathbf{s p}^{\mathbf{3}}\right)$ centered radical: MacMillan, Molander, Doyle, Rueping When $\mathrm{R} \cdot$ is a heteroatom centered radical: Johannes, Molander, Xiao, Rueping

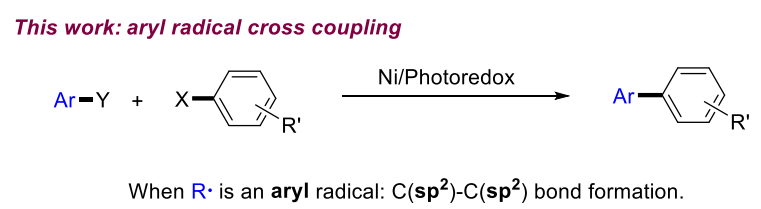

Therefore, we took the endeavor to photochemically generate an aryl radical and use it in a nickel/photoredox catalytic cycle to perform aryl-aryl reductive cross-couplings (Scheme 1). Reductive cross-coupling reactions of $\mathrm{C}\left(\mathrm{sp}^{2}\right)$ electrophiles have been extensively studied since the discovery of the Ullmann reaction. ${ }^{8,9}$ However, they involve either superstoichiometric amounts of metallic reducing agents ( $\mathrm{Zn}, \mathrm{Mn}$, $\mathrm{Mg}$ etc. $)^{8}$ or sacrificial metallic electrodes $(\mathrm{Zn}, \mathrm{Mg}, \mathrm{Fe})^{9}$ which produce substantial amount of metal-waste. In this regard, our method could offer a valuable alternative as we aimed to use an organic reductant ${ }^{10}$ (e.g. an amine) for the reductive quenching of the photocatalyst.

Scheme 1. 
Under photoredox conditions, aryl halides ranging from aryl iodides ${ }^{11}$ to polyfluoroarenes ${ }^{12}$ have been successfully reduced to the corresponding aryl radicals via electron transfer. As such, we started our investigation with electron-deficient pentafluoropyridine (1a) as radical precursor since it gives a longer-lived radical anion upon single-electron-reduction. ${ }^{12}$ In the initial trials, 1a was subjected to reaction with 2-naphthyl triflate in the presence of $\operatorname{Ir}(\mathrm{ppy})_{3}$ as photocatalyst under irradiation with blue LED strips with DIPEA $\left({ }^{i} \mathrm{Pr}_{2} \mathrm{NEt}\right)$ as reducing agent and acetonitrile as solvent. Unfortunately, none of the three different nickel salts used along with a phosphine ligand gave rise to our desired product (see Supporting Information, Table S1). However, we observed trace amount of the hydrodefluorinated side-product in GC-MS. ${ }^{11 \mathrm{~d}}$ This observation is in line with the findings of Weaver ${ }^{12 a, f}$ and Hashmi ${ }^{12 \mathrm{e}}$ in their C-F functionalization approach. Assuming that the DIPEA radical cation $\left[{ }^{i} \mathrm{Pr}_{2} \mathrm{NEt}\right]^{\bullet+}$ is the source of $\mathrm{H}$-atoms (see also Scheme 5a), we hoped that a tertiary amine with no $\alpha$ hydrogen atoms could furnish the desired product. However, using triphenylamine under otherwise identical conditions failed as well. Notably, the hydrodefluorinated side-product was not observed any more. Switching to other nickel salts, solvents and ligands did not improve the reaction outcome either.

Table 1. Optimization of the reaction conditions ${ }^{a}$

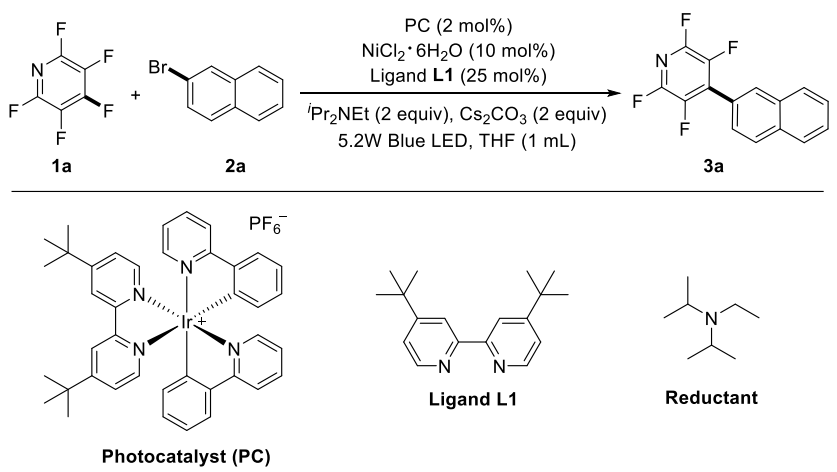

\begin{tabular}{lll} 
entry & deviation from standard conditions & \multicolumn{1}{c}{ result } \\
$\mathbf{1}$ & none & $65 \%^{b}$ \\
$\mathbf{2}$ & 1 equiv of 1a was used & $43 \%^{c}$ \\
$\mathbf{3}$ & 1 equiv 1a and 2 equiv 2a was used & $55 \%^{c}$ \\
$\mathbf{4}$ & 1.5 equiv of ${ }^{i} \mathrm{Pr}_{2} \mathrm{NEt}$ used & $61 \%^{b}$ \\
$\mathbf{5}$ & Without photocatalyst & No reaction \\
$\mathbf{6}$ & Without $\mathrm{NiCl}_{2} \cdot 6 \mathrm{H}_{2} \mathrm{O}$ & No desired \\
& & product \\
$\mathbf{7}$ & Without ${ }^{i} \mathrm{Pr}_{2} \mathrm{NEt}$ & No reaction \\
$\mathbf{8}$ & In the dark & No reaction
\end{tabular}

${ }^{a}$ Reaction conditions: $\mathbf{1 a}(0.2 \mathrm{mmol}, 2$ equiv), $\mathbf{2 a}(0.1 \mathrm{mmol}, 1$ equiv), photocatalyst $(0.002 \mathrm{mmol}, 2 \mathrm{~mol} \%)$, nickel salt $(0.01$ mmol, $10 \mathrm{~mol} \%)$, L1 (0.025 mmol, $25 \mathrm{~mol} \%)$, amine (0.2 mmol, 2 equiv) and base ( $0.2 \mathrm{mmol}, 2$ equiv) in $1 \mathrm{~mL}$ of solvent under argon for $22 \mathrm{hrs}$; ${ }^{b}$ Yield after isolation; ${ }^{c} \mathrm{NMR}$ yield calculated from ${ }^{19} \mathrm{~F}$ NMR with $\mathrm{PhCF}_{3}(0.2 \mathrm{mmol})$ as internal standard; ${ }^{d} \mathbf{1 a}$ remaining: $39 \%$; HDF side-product: $12 \%$.

We hypothesized that the $\mathrm{H}$-atom donation from $\left[{ }^{i} \mathrm{Pr}_{2} \mathrm{NEt}\right]^{\bullet+}$ could be suppressed by deprotonating the $\alpha$-position with a stronger base as shown by Hashmi and Weaver. ${ }^{13,12 \mathrm{~b}, \mathrm{e}, \mathrm{h}}$ Also, a photocatalyst which is cationic in its ground-state [unlike $\left.\operatorname{Ir}(\text { ppy })_{3}\right]$, might stabilize the $\left[\mathrm{C}_{5} \mathrm{~F}_{5} \mathrm{~N}\right]^{\bullet-}$ radical anion. ${ }^{12 \mathrm{e}}$ Therefore, we decided to conduct the reaction replacing $\operatorname{Ir}(\mathrm{ppy})_{3}$ with $\left[\operatorname{Ir}(\mathrm{ppy})_{2} \mathrm{dtbbpy}\right] \mathrm{PF}_{6}$ in the presence of an inorganic base i.e. cesium carbonate. However, formation of side-products arising from the hydrolysis of the triflate substrate was observed. To avoid that, we changed the electrophile to 2-bromo naphthalene (2a) and interestingly, the desired cross-coupling product was observed while conducting the reaction in THF. Pleasingly, with addition of $\mathrm{Cs}_{2} \mathrm{CO}_{3}$, the desired crosscoupling product 3a was isolated in $65 \%$ yield and excellent para-selectivity (Table1, entry 1). Varying the stoichiometry of the substrates led to lower yields (entries 2-3). The reaction also worked with similar efficiency with 1.5 equivalents of DIPEA (entry 4). Finally, control experiments showed that each component (photocatalyst, nickel salt, reductant and irradiation) is essential for the reaction to occur (entries 5-8).

\section{Scheme 2. Scope of bromoarenes ${ }^{a}$}
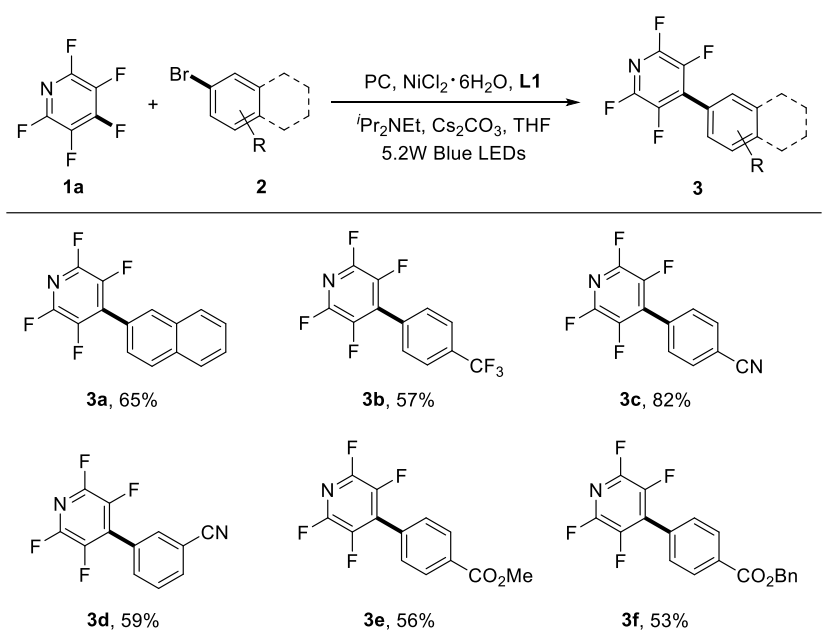

$3 c, 82 \%$
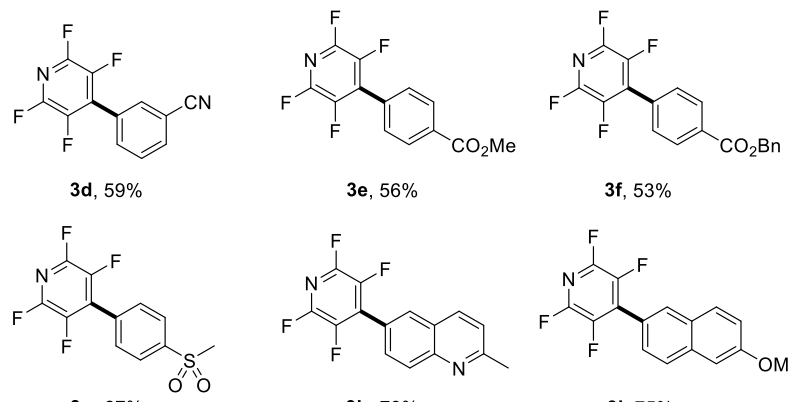

$3 h, 73 \%$

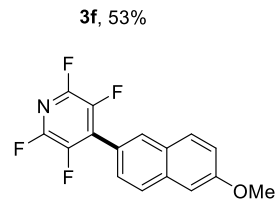

$3 \mathbf{i}, 75 \%$

${ }^{a}$ Reaction conditions: $1 \mathrm{a}(0.2 \mathrm{mmol}, 2$ equiv $), 2$ ( $0.1 \mathrm{mmol}, 1$ equiv), photocatalyst $(0.002 \mathrm{mmol}, 2 \mathrm{~mol} \%)$, nickel salt $(0.01$ mmol, $10 \mathrm{~mol} \%)$, L1 (0.025 mmol, $25 \mathrm{~mol} \%),{ }^{i} \operatorname{Pr}_{2} \mathrm{NEt}(0.2 \mathrm{mmol}$, 2 equiv) and $\mathrm{Cs}_{2} \mathrm{CO}_{3}(0.2 \mathrm{mmol}, 2$ equiv) in THF ( $1 \mathrm{~mL})$ under argon for $22 \mathrm{hrs}$.

With the optimized reaction conditions in hand, we explored the scope of the reaction with respect to bromoarenes bearing various substituents and the results are summarized in Scheme 2. Highly electron deficient 4-bromo benzotrifluoride gave the desired cross-coupling product $\mathbf{3 b}$ in $57 \%$ yield. The cyano group was tolerated both in the para $(82 \%)$ and meta $(59 \%)$ positions with good to excellent yields (3c and 3d). Esters of bromo substituted benzoic acids worked efficiently as well. The methyl and the benzyl derivatives gave the corresponding desired products $\mathbf{3 e}$ and $\mathbf{3 f}$ in $56 \%$ and $53 \%$ yields, respectively. The coupling product $3 \mathrm{~g}$ was isolated in $67 \%$ yield when methyl-(4-bromo phenyl)-sulfone was treated with 1a. In addition, a heteroaromatic system, bromoquinoline $\mathbf{2 h}$ was also tested and performed well in the desired cross-coupling 
reaction, affording $\mathbf{3 h}$ in good yield (73\%). To our delight, beside electron-poor arenes, electron-rich naphthalene $\mathbf{2 i}$ also showed excellent reactivity to form $\mathbf{3 i}(75 \%)$.

Next, we tested the reactivity of aryl iodides (Scheme 3). Our first attempt with para-iodo toluene afforded $\mathbf{3 j}$ in $75 \%$ yield. $M e t a$-iodo toluene and para-ethyl iodobenzene also reacted well to produce the corresponding coupling products $\mathbf{3 k}$ and $\mathbf{3 1}$ in good yields (81\% and 65\%). Derivative 3m was produced in $62 \%$ yield when the corresponding substrate containing a tert-butyl group was treated with 1a. Notably, electron rich para-iodo anisole also furnished biaryl 3n efficiently $(65 \%)$. Acetal functional group was also tolerated on the iodoarene giving the desired product 3o in 70\% yield. Electron-poor 4fluoroiodobenzene gave the biaryl $\mathbf{3 p}$ in $51 \%$ yield. Iodobiphenyl reacted with moderate efficiency and we could isolate $\mathbf{3 q}$ in $47 \%$ yield.

\section{Scheme 3. Scope of iodoarenes ${ }^{a}$}
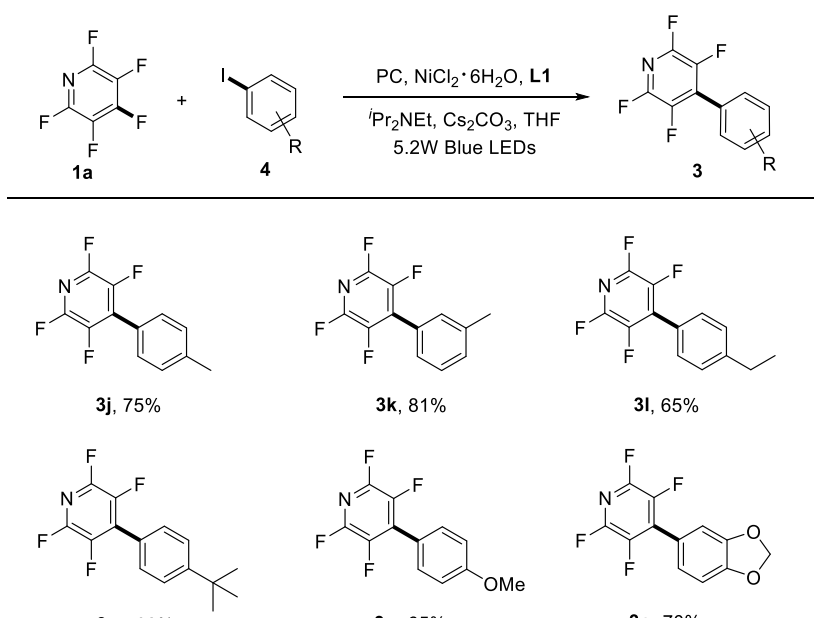

$3 \mathrm{~m}, 62 \%$

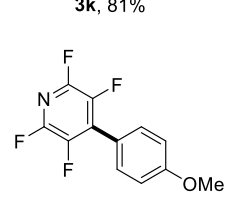

3n, $65 \%$

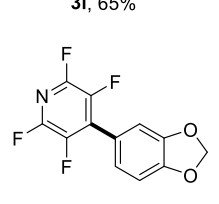

3o, $70 \%$

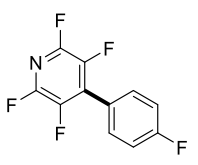

$3 p, 51 \%$

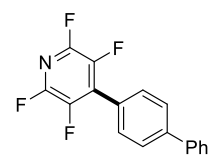

$3 q, 47 \%$
${ }^{a}$ Reaction conditions: 1a (0.2 mmol, 2 equiv), 4 (0.1 mmol, 1 equiv), photocatalyst $(0.002 \mathrm{mmol}, 2 \mathrm{~mol} \%)$, nickel salt $(0.01$ mmol, $10 \mathrm{~mol} \%)$, L1 (0.025 mmol, $25 \mathrm{~mol} \%),{ }^{i} \operatorname{Pr}_{2} \mathrm{NEt}(0.2 \mathrm{mmol}$, 2 equiv) and $\mathrm{Cs}_{2} \mathrm{CO}_{3}(0.2 \mathrm{mmol}, 2$ equiv) in THF (1 mL) under argon for $22 \mathrm{hrs}$.

It is worth mentioning that unlike the bromoarenes, the iodoarenes worked with fairly electron rich substrates. This indicates that the ease of oxidative addition by nickel is important for a successful reaction.

We next tested the reactivity of other polyfluorinated arenes under our optimized conditions (Scheme 4). We chose iodoarenes as coupling partners as they showed better reactivity compared to bromoarenes. Reaction of octafluorotoluene (1b) with four different iodoarenes resulted in the desired products 5a-d with moderate yields. ${ }^{14}$ Next, we applied pentafluorobenzonitrile (1c) in reaction with 4-iodo toluene, and, to our delight, it gave the coupling product $\mathbf{6 a}$ in an excellent yield of $90 \%$. Replacing the methyl group with ethyl and tert-butyl did not affect the reactivity and $\mathbf{6 b}$ and $\mathbf{6 c}$ were isolated in $89 \%$ and $78 \%$ yield, respectively. Use of other perfluoroarenes resulted in either trace amount of product or no reaction. We performed the reaction to obtain $6 \mathbf{a}$ in $1.0 \mathrm{mmol}$ scale and isolated the desired product in $66 \%$ yield (for detailed procedure, see SI).

\section{Scheme 4. Scope of polyfluoroarenes ${ }^{a}$}

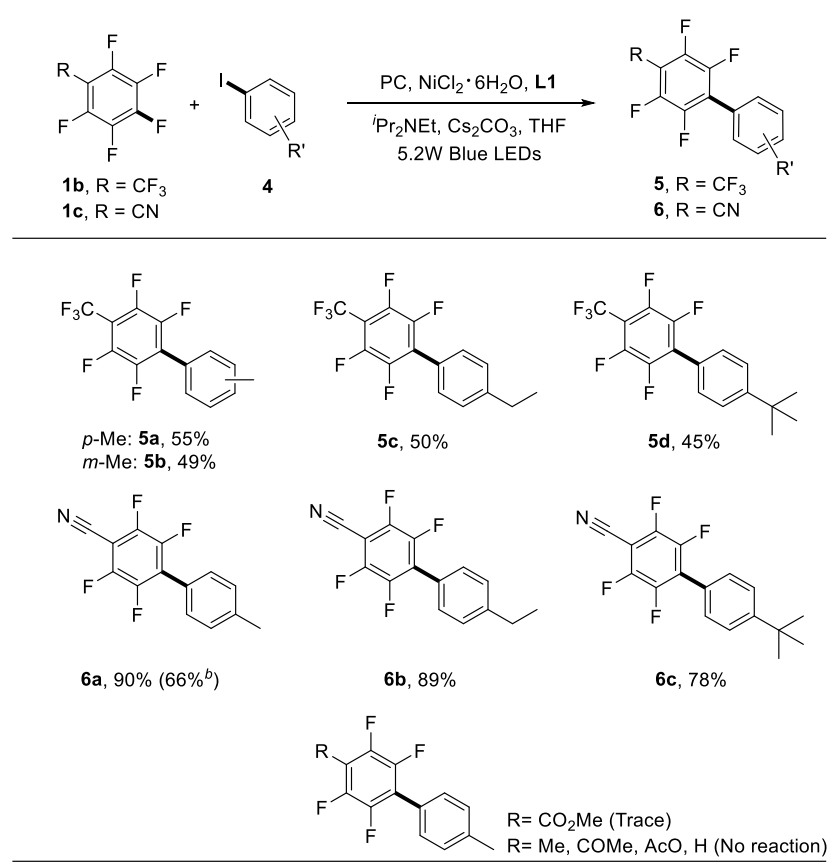

${ }^{a}$ Reaction conditions: $\mathbf{1 b} / \mathbf{c}(0.2 \mathrm{mmol}, 2$ equiv), 4 ( $0.1 \mathrm{mmol}, 1$ equiv), photocatalyst $(0.002 \mathrm{mmol}, 2 \mathrm{~mol} \%)$, nickel salt $(0.01$ $\mathrm{mmol}, 10 \mathrm{~mol} \%)$, L1 (0.025 mmol, $25 \mathrm{~mol} \%),{ }^{i} \operatorname{Pr}_{2} \mathrm{NEt}(0.2 \mathrm{mmol}$, 2 equiv) and $\mathrm{Cs}_{2} \mathrm{CO}_{3}$ (0.2 mmol, 2 equiv) in THF (1 mL) under argon for $22 \mathrm{hrs} .{ }^{b}$ Reaction performed on $1 \mathrm{mmol}$ scale.

As mentioned before, 2,3,5,6-tetrafluoropyridine (7) was observed as a side-product during the optimization studies. It indicates to an electron transfer process to 1a with the generation of the radical anion $\left[\mathrm{C}_{5} \mathrm{~F}_{5} \mathrm{~N}\right]^{\bullet-}$. Subsequent $\mathrm{H}$-atom abstraction from ${ }^{i} \mathrm{Pr}_{2} \mathrm{NEt}^{\circ+}$ (in absence of $\mathrm{Cs}_{2} \mathrm{CO}_{3}$ ) and $\mathrm{F}^{-}$elimination, gives rise to the hydrodefluorinated product 7 (Scheme 5a).

However, it may also be envisaged that iodoarenes can be reduced via SET under these conditions. This competition could be avoided by choosing electron-rich and difficult to reduce aryl iodides. To confirm our hypothesis, we performed control experiments (see SI, Table S2). $\mathrm{C}_{5} \mathrm{~F}_{5} \mathrm{~N}$ was irradiated under the optimized conditions in the absence of the nickel salt and ligand and in the presence of 4-iodotoluene, 4-iodo ethylbenzene and 4-iodo tert-butyl benzene, in three separate experiments. The nickel catalytic components were left out in order to test the difference in reactivity between 19 and iodoarenes towards SET.

In all three cases, the perfluoroarene showed higher conversion than the iodoarene after 8 hours. Under our optimized conditions, where the nickel catalyst is present, the SET to ArI will be even more suppressed due to an efficient oxidative addition. The major products were perfluoroarylated analogues of DIPEA and THF along with the hydrodeiodinated product (see SI). Notably, ${ }^{19} \mathrm{~F}$ NMR analysis (prior to work up) showed that the hydrodefluorinated product formation was suppressed owing to the presence of $\mathrm{Cs}_{2} \mathrm{CO}_{3}$. Thus, we decided to investigate whether the unpaired-electron species inter- 
cepted by the $\mathrm{Ni}$ complex is the stabilized radical anion $\left[\mathrm{C}_{5} \mathrm{~F}_{5} \mathrm{~N}\right]^{\bullet-}$ or the ${ }^{\bullet} \mathrm{C}_{5} \mathrm{~F}_{4} \mathrm{~N}$ radical. In principle, the ${ }^{\bullet} \mathrm{C}_{5} \mathrm{~F}_{4} \mathrm{~N}$ radical formed via fluoride fragmentation at the 4-position, should be too unstable to selectively couple with $\mathrm{Ni}$. Instead, it will immediately undergo fast side-reactions with other more abundant reaction components (e.g. HAT from solvent). Therefore, we decided to test the 4-chloro and 4-bromo analogue of $1 \mathbf{a}$ as the perfluoroarene source (Scheme 5b). As per our expectations, $\mathrm{Cl}-\mathrm{C}_{5} \mathrm{~F}_{4} \mathrm{~N}$ gave a diminished yield of $56 \%$ (determined by NMR) and $\mathrm{Br}-\mathrm{C}_{5} \mathrm{~F}_{4} \mathrm{~N}$ gave only $5 \%$ of the desired product $\mathbf{3 j}$. This observation is in line with the relative rate of fragmentation of halides, i.e., $\mathrm{F}^{-}<\mathrm{Cl}^{-}<\mathrm{Br}^{-}$and indicates that the radical anion $\left[\mathrm{C}_{5} \mathrm{~F}_{5} \mathrm{~N}\right]^{\bullet-}$ is more prone to be trapped by $\mathrm{Ni}$, instead of ${ }^{\circ} \mathrm{C}_{5} \mathrm{~F}_{4} \mathrm{~N}$ radical. Besides, this observation also rules out a mechanism where $\mathrm{Ni}^{0}$ oxidatively adds to the $\mathrm{C}-\mathrm{F}$ bond and the subsequent $\mathrm{Ni}^{\mathrm{II}}$ species traps an aryl radical from aryl iodide- because, in such a case, the reaction with $\mathrm{Br}$ $\mathrm{C}_{5} \mathrm{~F}_{4} \mathrm{~N}$ should have provided a substantial amount of desired coupling product.

\section{Scheme 5. Side reaction and mechanistic experiments.}

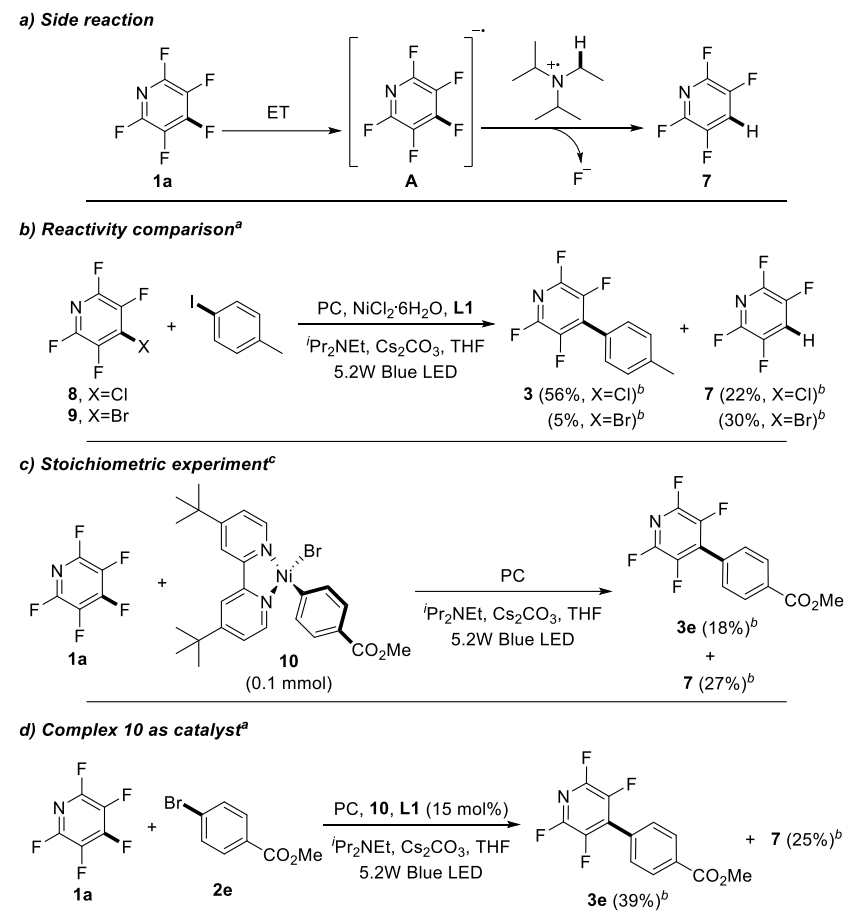

${ }^{a}$ Reaction conditions: 8/9/1a (0.2 mmol, 2 equiv $)$, 4iodotoluene $/ 2 \mathrm{e}$ ( $0.1 \mathrm{mmol}, 1$ equiv), photocatalyst $(0.002 \mathrm{mmol}, 2$ mol\%), nickel salt (0.01 mmol, $10 \mathrm{~mol} \%), \mathbf{L 1}(0.025 \mathrm{mmol}, 25$ mol\%), ${ }^{i} \operatorname{Pr}_{2} \mathrm{NEt}\left(0.2 \mathrm{mmol}, 2\right.$ equiv) and $\mathrm{Cs}_{2} \mathrm{CO}_{3}(0.2 \mathrm{mmol}, 2$ equiv) in THF (1 mL) under argon for $22 \mathrm{hrs;}{ }^{b} \mathrm{NMR}$ yield calculated from ${ }^{19} \mathrm{~F}$ NMR with $\mathrm{PhCF}_{3}(0.2 \mathrm{mmol})$ as internal standard; ${ }^{c}$ Reaction conditions: 19 ( $0.2 \mathrm{mmol}, 2$ equiv), $10(0.1 \mathrm{mmol}, 1$ equiv), photocatalyst (0.002 mmol, $2 \mathrm{~mol} \%),{ }^{i} \operatorname{Pr}_{2} \mathrm{NEt}(0.2 \mathrm{mmol}$, 2 equiv) and $\mathrm{Cs}_{2} \mathrm{CO}_{3}(0.2 \mathrm{mmol}, 2$ equiv) in THF $(1 \mathrm{~mL})$ under argon for $22 \mathrm{hrs}$.

Next, we shifted our focus to identify the Ni species that traps the $\left[\mathrm{C}_{5} \mathrm{~F}_{5} \mathrm{~N}\right]^{\bullet-}$. The two most probable candidates are $\mathrm{Ni}^{0}$ and Ar-Ni ${ }^{\mathrm{II}}-\mathrm{X}$ (formed via oxidative addition of $\mathrm{Ni}^{0}$ to $\mathrm{ArX}$ ) complexes. Therefore, we prepared such a $\mathrm{Ni}^{\mathrm{II}}$ complex $\mathbf{1 0}$ and subjected $0.1 \mathrm{mmol}$ of that under identical photochemical reaction conditions (Scheme 5c). Interestingly, 18\% (NMR yield) of desired cross-coupled product was formed (average of two experiments). This shows us that, $\mathrm{Ar}-\mathrm{Ni}^{\mathrm{II}}-\mathrm{X}$ can intercept $\mathbf{A}$. In a separate experiment, when we used the complex $\mathbf{1 0}$ as the nickel catalyst in our otherwise unchanged reaction conditions, the NMR yield of $\mathbf{3 e}$ increased to $39 \%$ (Scheme 5d). In this case, the nickel catalytic cycle is initiated by $\mathbf{1 0}$ intercepting $\mathbf{A}$, thereby prompting us to propose a similar mechanism for our reactions as well, where $\mathrm{NiCl}_{2} 6 \mathrm{H}_{2} \mathrm{O}$ is used as catalyst (Scheme 6).

Based on our observations and previous reports on both $\mathrm{Ni} /$ photoredox $^{15}$ and polyfluoroarene systems, ${ }^{12 a, e, f}$ a plausible mechanism is outlined in Scheme 6. In the first step, ${ }^{i} \operatorname{Pr}_{2} \mathrm{NEt}$ $\left[E_{1 / 2}{ }^{\text {ox }}=+0.68 \mathrm{~V} \text { vs. SCE }\right]^{16 \mathrm{a}}$ is oxidized by the photoexcited $*{ }^{\mathrm{IIII}}\left[E\left(* \mathrm{Ir}^{\mathrm{III} /} \mathrm{Ir}^{\mathrm{II}}\right)=+0.66 \mathrm{~V} \text { vs.SCE}\right]^{16 \mathrm{~b}}$ to give a highly reducing $\operatorname{Ir}^{\mathrm{II}}\left[E\left(\mathrm{Ir}^{\mathrm{III} / \mathrm{II}}\right)=-1.51 \mathrm{~V} \text { vs. SCE }\right]^{16 \mathrm{~b}}$ species. The $\mathrm{Ir}^{\mathrm{II}}$ then makes an endergonic electron transfer to $\mathrm{C}_{5} \mathrm{~F}_{5} \mathrm{~N}\left[E_{1 / 2}{ }^{\text {red }}=\right.$ $-2.12 \mathrm{~V}$ vs. SCE] driven by the electrostatic stabilization of $\left[\mathrm{C}_{5} \mathrm{~F}_{5} \mathrm{~N}\right]^{--}$by the ground-state cationic $\mathrm{Ir}^{\mathrm{III}}$ photocatalyst. ${ }^{12 \mathrm{e}}$ Subsequently, the stabilized and longer-lived radical anion $\mathbf{A}$ reacts with a $\mathrm{Ni}^{\mathrm{II}}$ species $\mathbf{B}$ to form $\mathrm{Ni}^{\mathrm{III}}$ intermediate $\mathbf{C}$ after $\mathrm{F}^{-}$elimination. Upon subsequent reductive elimination, the cross-coupling product and $\mathrm{Ni}^{\mathrm{I}}$ complex $\mathbf{D}$ are formed. Finally, D is reduced via electron transfer to give $\mathrm{Ni}^{0}$ which does oxidative addition to the aryl halide to regenerate $\mathbf{B}$ and that completes the catalytic cycle. The other plausible underlying mechanism where $\mathrm{Ni}^{0}$ traps the $\left[\mathrm{C}_{5} \mathrm{~F}_{5} \mathrm{~N}\right]^{\bullet-}$ first and the resulting $\mathrm{Ni}^{\mathrm{I}}$ complex $\mathbf{E}$ oxidatively adds to the aryl halide is also depicted in Scheme $6 .^{17}$

\section{Scheme 6. Plausible mechanism.}

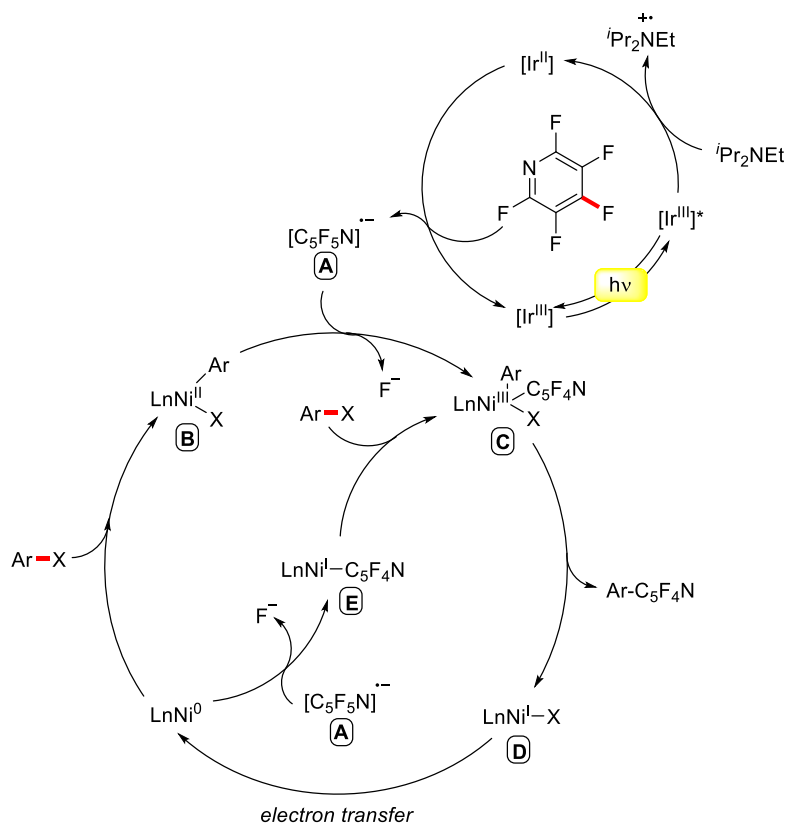

In conclusion, we described the first reductive aryl-aryl crosscoupling utilizing a combination of photoredox and nickel catalysis. The stability of the resulting radical anion arising from the reduction of polyfluoroarenes was exploited in reaction with a catalytic nickel intermediate. The transformation could be applied to the synthesis of multifluorinated compounds in moderate to excellent yields, starting from different aryl fluorides and a broad scope of electron-rich as well as 
electron-deficient aryl bromides and iodides. The use of an organic reducing agent instead of a metal reductant, mild reaction conditions, and an excellent para-selectivity make this approach a valuable alternative to reported reductive cross-coupling methods.

\section{ASSOCIATED CONTENT}

\section{Supporting Information}

The Supporting Information is available free of charge on the ACS Publications website.

Supplementary table for optimization, detailed experimental procedure, spectral data and ${ }^{1} \mathrm{H},{ }^{13} \mathrm{C}$ and ${ }^{19} \mathrm{~F}$ spectra for all compounds.

\section{AUTHOR INFORMATION}

\section{Corresponding Author}

* E-mail: magnus.rueping@ @rwth-aachen.de.

\section{Funding Sources}

The research leading to these results has received funding from the European Research Council under the European Union's Seventh Framework Programme (FP/2007-2013) / ERC Grant Agreement no. 617044 (SunCatChem).

\section{Notes}

Any additional relevant notes should be placed here.

\section{ACKNOWLEDGEMENT}

We thank Frau Cornelia Vermeeren for carrying out purifications by preparative HPLC.

\section{ABBREVIATIONS}

LED, Light-Emitting Diode; DIPEA, Diisopropylethylamine; THF, Tetrahydrofuran; SI, Supporting Information; PC, Photocatalyst; GC-MS, Gas Chromatography-Mass Spectrometry; HPLC, High-performance Liquid Chromatography; HAT, Hydrogen Atom Transfer.

\section{REFERENCES}

(1) (a) Twilton, J.; Le, C.; Zhang, P.; Shaw, M. H.; Evans, R. W.; MacMillan, D. W. C. The merger of transition metal and photocatalysis. Nat. Rev. Chem. 2017, 1, 0052. (b) Matsui, J. K.; Lang, S. B.; Heitz, D. R.; Molander, G. A. Photoredox-Mediated Routes to Radicals: The Value of Catalytic Radical Generation in Synthetic Methods Development. ACS Catal. 2017, 7, 2563-2575. (c) Tellis, G. C.; Kelly, C. B.; Primer, D. N.; Jouffroy, M.; Patel, N. R.; Molander, G. A. Single-Electron Transmetalation via Photoredox/Nickel Dual Catalysis: Unlocking a New Paradigm for $\mathrm{sp}^{3}-\mathrm{sp}^{2}$ Cross-Coupling. Acc. Chem. Res. 2016, 49, 1429-1439. (d) Gui, Y-Y.; Sun, L.; Lu, ZP.; Yu, D-G. Photoredox sheds new light on nickel catalysis: from carbon-carbon to carbon-heteroatom bond formation. Org. Chem. Front. 2016, 3, 522-526. (e) Vila, C. Merging Visible-LightPhotoredox and Nickel Catalysis. ChemCatChem 2015, 7, 1790-1793. (f) Skubi, K. L.; Blum, T. R.; Yoon, T. P. Dual Catalysis Strategies in Photochemical Synthesis. Chem. Rev. 2016, 116, 10035-10074. (g) Fabry, D. C.; Rueping, M. Merging Visible Light Photoredox Catalysis with Metal Catalyzed $\mathrm{C}-\mathrm{H}$ Activations: On the Role of Oxygen and Superoxide Ions as Oxidants. Acc. Chem. Res. 2016, 49, 19691979.

(2) (a) Zoller, J.; Fabry, D. C.; Ronge, M. A.; Rueping, M. Synthesis of Indoles Using Visible Light: Photoredox Catalysis for Palladi-
um-Catalyzed C-H Activation. Angew. Chem., Int. Ed. 2014, 53, 13264-13268. (b) Fabry, D. C.; Zoller, J.; Raja, S.; Rueping, M. Combining Rhodium and Photoredox Catalysis for C-H Functionalizations of Arenes: Oxidative Heck Reactions with Visible Light. Angew. Chem. Int. Ed. 2014, 53, 10228-10231. (c) Fabry, D. C.; Ronge, M. A.; Zoller, J.; Rueping, M. C-H Functionalization of Phenols Using Combined Ruthenium and Photoredox Catalysis: In Situ Generation of the Oxidant. Angew. Chem., Int. Ed. 2015, 54, 2801-2805. (d) Terrett, J. A.; Cuthbertson, J. D.; Shurtleff, V. W.; MacMillan, D. W. C. Switching on elusive organometallic mechanisms with photoredox catalysis. Nature 2015, 524, 330-334. (e) Le, C.; MacMillan, D. W. C. Fragment Couplings via $\mathrm{CO}_{2}$ ExtrusionRecombination: Expansion of a Classic Bond-Forming Strategy via Metallaphotoredox. J. Am. Chem. Soc. 2015, 137, 11938-11941. (f) Tasker, S. Z.; Jamison, T. F. Highly Regioselective Indoline Synthesis under Nickel/Photoredox Dual Catalysis. J. Am. Chem. Soc. 2015 , 137, 9531-9534. (g) Lang, S. B.; O’Nele, K. M.; Tunge, J. A. Decarboxylative Allylation of Amino Alkanoic Acids and Esters via Dual Catalysis. J. Am. Chem. Soc. 2014, 136, 13606-13609. (h) Cai, Y.; Tang Y.; Fan, L.; Lefebvre, Q.; Hou, H.; Rueping, M. Heterogeneous Visible-Light Photoredox Catalysis with Graphitic Carbon Nitride for $\alpha$-Aminoalkyl Radical Additions, Allylations and Heteroarylations. ACS Catal. 2018, 8, 9471-9476; (i) Fabry, D. C.; Zoller, J.; Rueping, M. Semiconductors as Heterogeneous Visible Light Photoredox Catalysts in Combined Dual Metal Catalyzed C-H Functionalizations, Org. Chem. Front. 2019, 6, 2635-2639. (j) Kim, H.-J.; Fabry, D. C.; Mader, S.; Rueping, M. Photoredox/ Rhodium catalysis in C-H activation for the synthesis of nitrogen containing heterocycles, Org. Chem. Front. 2019, 6, 2319-2323. (k) Kalsi, D.; Barsu, N.; Chakrabarti, S.; Dahiya, P.; Rueping, M.; Sundararajua, B. C-H and $\mathrm{N}-\mathrm{H}$ Bond Annulation of Aryl Amides with Unactivated Olefins by Merging Cobalt(III) and Photoredox Catalysis. Chem. Commun., 2019, 55, 11626-11629

(3) (a) Yoo, W.-J.; Tsukamoto, T.; Kobayashi, S. Visible LightMediated Ullmann-Type C-N Coupling Reactions of Carbazole Derivatives and Aryl Iodides. Org. Lett. 2015, 17, 3640-3642. (b) Welin, E. R.; Le, C.; Arias-Rotondo, D. M.; McCusker, J. K.; MaMillan, D. W. C. Photosensitized, energy transfer-mediated organometallic catalysis through electronically excited nickel(II). Science, 2017, 355, 380-385. (c) Heitz, D. R.; Tellis, J. C.; Molander G. A. Photochemical Nickel-Catalyzed C-H Arylation: Synthetic Scope and Mechanistic Investigations. J. Am. Chem. Soc. 2016, 138, 1271512718. (d) Huang, L.; Rueping, M Direct Cross-Coupling of Allylic $\mathrm{C}\left(\mathrm{sp}^{3}\right)-\mathrm{H}$ Bonds with Aryl- and Vinylbromides by Combined Nickel and Visible-Light Catalysis. Angew. Chem. Int. Ed. 2018, 57,1033310337. (e) Tian, Y.-M.; Guo, X.-N.; Kuntze-Fechner, M. W.; Krummenacher, I.; Braunschweig, H.; Radius, U.; Steffen, A.; Marder, T. B. Selective Photocatalytic C-F Borylation of Polyfluoroarenes by Rh/Ni Dual Catalysis Providing Valuable Fluorinated Arylboronate Esters. J. Am. Chem. Soc. 2018, 140, 1761217623.

(4) (a) Zuo, Z.; Ahneman, D. T.; Chut, L.; Terrett, J. A.; Doyle, A. G.; MacMillan, D. W. C. Merging photoredox with nickel catalysis: Coupling of $\alpha$-carboxyl $\mathrm{sp}^{3}$-carbons with aryl halides. Science $\mathbf{2 0 1 4}$, 345, 437-440. (b) Tellis, J. C.; Primer, D. N.; Molander, G. A. Singleelectron transmetalation in organoboron cross-coupling by photoredox/nickel dual catalysis. Science 2014, 345, 433-436. (c) Kalyani, D.; McMurtrey, K. B.; Neufeldt, S. R.; Sanford, M. S. RoomTemperature C-H Arylation: Merger of Pd-Catalyzed C-H Functionalization and Visible-Light Photocatalysis. J. Am. Chem. Soc. 2011, 133, 18566-18569. (d) Sahoo, B.; Hopkinson, M. N.; Glorius, F. Combining Gold and Photoredox Catalysis: Visible Light-Mediated Oxy- and Aminoarylation of Alkenes. J. Am. Chem. Soc. 2013, 135, 5505-5508. (e) Freeman, D. B.; Furst, L.; Condie, A. G.; Stephenson, C. R. J. Functionally Diverse Nucleophilic Trapping of Iminium Intermediates Generated Utilizing Visible Light. Org. Lett. 2012, 14, 94-97. (f) Rueping, M.; Koenigs, R. M.; Poscharny, K.; Fabry, D. C.; Leonori, D.; Vila, C. Dual Catalysis: Combination of Photocatalytic Aerobic Oxidation and Metal Catalyzed Alkynylation Reactions-CC Bond Formation Using Visible Light. Chem. Eur. J. 2012, 18, 5170-5174. (g) Ye, Y.; Sanford, M. Merging Visible-Light Photoca- 
talysis and Transition-Metal Catalysis in the Copper-Catalyzed Trifluoromethylation of Boronic Acids with $\mathrm{CF}_{3} \mathrm{I}$. J. Am. Chem. Soc. 2012, 134, 9034-9037. (h). Shields, B. J.; Doyle, A. G. Direct C( $\left.\mathrm{sp}^{3}\right)_{-}$ H Cross Coupling Enabled by Catalytic Generation of Chlorine Radicals. J. Am. Chem. Soc. 2016, 138, 12719-12722. (i) Duan, Z.; Li, W.; Lei, A. Nickel-Catalyzed Reductive Cross-Coupling of Aryl Bromides with Alkyl Bromides: $\mathrm{Et}_{3} \mathrm{~N}$ as the Terminal Reductant. Org. Lett. 2016, 18, 4012-4015. (j) Paul, A.; Smith, M. D.; Vannucci, A. K. Photoredox-Assisted Reductive Cross-Coupling: Mechanistic Insight into Catalytic Aryl-Alkyl Cross-Couplings. J. Org. Chem. 2017, 82, 1996-2003. (k) Fan, L.; Jia, J.; Hou, H.; Lefebvre, Q.; Rueping, M. Decarboxylative Aminomethylation of Aryl- and Vinylsulfonates through Combined Nickel- and Photoredox-Catalyzed CrossCoupling. Chem. Eur. J. 2016, 22, 16437-16440. (1) Shaw, M.; H., Shurtleff, V. W.; Terrett, J. A.; Cuthbertson, J. D.; MacMillan, D. W. C. Native functionality in triple catalytic cross-coupling: $\mathrm{sp}^{3} \mathrm{C}-\mathrm{H}$ bonds as latent nucleophiles. Science 2016, 352, 1304-1308. (m) Le, C.; Liang, Y.; Evans, R. W.; Li, X.; MacMillan, D. W. C. Selective $\mathrm{sp}^{3} \mathrm{C}-\mathrm{H}$ alkylation via polarity-match-based cross-coupling. Nature 2017, 547, 79-83. (n) Perry, I. B.; Brewer, T. F.; Sarver, P. J.; Schultz, D. M.; DiRocco, D. A.; MacMillan, D. W. C. Direct arylation of strong aliphatic C-H bonds. Nature 2018, 560, 70-75. (o) Zhang, P.; Le, C. C.; MacMillan, D. W. C. Silyl Radical Activation of Alkyl Halides in Metallaphotoredox Catalysis: A Unique Pathway for Cross-Electrophile Coupling J. Am. Chem. Soc. 2016, 138, 8084-8087. (p) Masuda, Y.; Ishida, N.; Murakami, M. Aryl Ketones as Single-Electron-Transfer Photoredox Catalysts in the NickelCatalyzed Homocoupling of Aryl Halides. Eur. J. Org. Chem. 2016, $5822-5825$.

(5) (a) Oderinde, M. S.; Frenette, M.; Robbins, D. W.; Aquila, B.; Johannes, J. W. Photoredox Mediated Nickel Catalyzed CrossCoupling of Thiols With Aryl and Heteroaryl Iodides via Thiyl Radicals. J. Am. Chem. Soc. 2016, 138, 1760-1763. (b) Jouffroy, M.; Kelly, C. B.; Molander, G. A. Thioetherification via Photoredox/Nickel Dual Catalysis. Org. Lett. 2016, 18, 876-879. (c) Xuan, J.; Zeng, T.-T.; Chen, J.-R.; Lu, L.-Q.; Xiao, W.-J. Room Temperature C-P Bond Formation Enabled by Merging Nickel Catalysis and Visible-Light-Induced Photoredox Catalysis. Chem. Eur. J. 2015, 21, 4962-4965. (d) Corcoran, E. B.; Pirnot, M. T.; Lin, S.; Dreher, S. D.; DiRoco, D. A.; Davies, I, W.; Buchwald, S. L.; MacMillan, D. W. C. Aryl amination using ligand-free $\mathrm{Ni}(\mathrm{II})$ salts and photoredox catalysis. Science 2016, 353, 279-283. (e) Oderinde, M. S.; Jones, N. H.; Juneau, A.; Frenette, M.; Aquila, B.; Tentarelli, S.; Robbins, D. W.; Johannes, J. W. Highly Chemoselective Iridium Photoredox and Nickel Catalysis for the Cross-Coupling of Primary Aryl Amines with Aryl Halides. Angew. Chem. Int. Ed. 2016, 55, 13219-13223; (f) Yue, H.; Zhu, C.; Rueping, M. Cross-Coupling of Sodium Sulfinates with Aryl, Heteroaryl, and Vinyl Halides by Nickel/Photoredox Dual Catalysis. Angew. Chem. Int. Ed. 2018, 57, 1371-1375. (g) Zhu, C.; Yue, H.; Maity, B.; Atodiresei, I.; Cavallo, L.; Rueping M. A multicomponent synthesis of stereodefined olefins via nickel catalysis and single electron/triplet energy transfer. Nat. Catal. 2019, 2, 678-687. (h) Dewanji, A.; Krach, P. E.; Rueping M. The Dual Role of Benzophenone in Visible-Light/Nickel Catalyzed C-H Arylations: Hydrogen Atom Transfer and Energy Transfer. Angew. Chem. Int. Ed. 2019, 58, 3566-3570. (i) Huang, L.; Zhu, C.; Yi, L.; Yue, H.; Kancherla, R.; Rueping, M. Cascade Cross Coupling of Dienes: Photoredox and Nickel Dual Catalysis. Angew. Chem. Int. Ed. 2020, 59, 457- 464

(6) (a) Chu, L.; Lipshultz, J. M.; MacMillan, D. W. C. Merging Photoredox and Nickel Catalysis: The Direct Synthesis of Ketones by the Decarboxylative Arylation of $\alpha$-Oxo Acids. Angew. Chem. Int. Ed. 2015, 54, 7929-7933. (b) Zhang, X.; MacMillan, D. W. C. Direct Aldehyde $\mathrm{C}-\mathrm{H}$ Arylation and Alkylation via the Combination of Nickel, Hydrogen Atom Transfer, and Photoredox Catalysis. J. Am. Chem. Soc. 2017, 139, 11353-11356.

(7) Studer, A.; Curran, D. P. Catalysis of Radical Reactions: A Radical Chemistry Perspective. Angew. Chem., Int. Ed. 2016, 55, 58102.

(8) (a) Knappke, C. E. I.; Grupe, S.; Gärtner, D.; Corpet, M.; Gosmini, C.; von Wangelin, A. J. Reductive Cross-Coupling Reactions between Two Electrophiles. Chem. Eur. J. 2014, 20, 6828-6842. (b)
Hassan, J.; Sevignon, M.; Gozzi, C.; Schulz, E.; Lemaire, M. Aryl-Aryl Bond Formation One Century after the Discovery of the Ullmann Reaction. Chem. Rev. 2002, 102, 1359-1469. (c) Moragas, T.; Correa, A.; Martin, R. Metal-Catalyzed Reductive Coupling Reactions of Organic Halides with Carbonyl-Type Compounds. Chem. Eur. J. 2014, 20, 8242-8258. (d) Ackerman, L. K. G.; Lovell, M. M.; Weix, D. J. Multimetallic catalysed cross-coupling of aryl bromides with aryl triflates. Nature 2015, 524, 454-457 (e) Everson, D. A.; Weix, D. J. Cross-Electrophile Coupling: Principles of Reactivity and Selectivity. J. Org. Chem. 2014, 79, 4793-4798. (f) Fanta, P. E. The Ullmann Synthesis of Biaryls. Chem. Rev. 1946, 38, 139-196. (g) Rosen, B. M.; Quasdorf, K. W.; Wilson, D. A.; Zhang, N.; Resmerita, A-M.; Garg, N. K.; Percec, V. Nickel-Catalyzed Cross-Couplings Involving Carbon-Oxygen Bonds Chem. Rev. 2011, 111, 1346-1416. (h) Bhattacharjya, A., Klumphu, P., Lipshutz, B. H. KumadaGrignard-type biaryl couplings on water Nat. Commun. 2015, 6, 7401.

(9) (a) Gomes, P.; Fillon, H.; Gosmini, C.; Labbé, E.; Périchon, J. Synthesis of unsymmetrical biaryls by electroreductive cobaltcatalyzed cross-coupling of aryl halides. Tetrahedron 2002, 58, $8417-$ 8424. (b) Gosmini, C.; Lasry, S.; Nedelec, J-Y.; Perichon, J. Electrochemical Cross-coupling Between 2-Halopyridines and Aryl or Heteroaryl Halides Catalysed by Nickel-2,2'-Bipyridine Complexes. Tetrahedron 1998, 54, 1289-1298. (c) Gosmini, C. Nédélec, J-Y.; Périchon, J. Electrosynthesis of functionalized 2-arylpyridines from functionalized aryl and pyridine halides catalyzed by nickel bromide 2,2' -bipyridine complex. Tetrahedron Lett., 2000, 41, 5039-5042. (d) Gosmini, C. Nédélec, J-Y.; Périchon, J. Electrochemical crosscoupling between functionalized aryl halides and 2-chloropyrimidine or 2-chloropyrazine catalyzed by nickel 2,2'-bipyridine complex. Tetrahedron Lett., 2000, 41, 201-203.

(10) Lv, L.; Qiu, Z.; Li, J.; Liu, M.; Li, C-J. $\mathrm{N}_{2} \mathrm{H}_{4}$ as traceless mediator for homo- and cross- aryl coupling. Nat. Commun. 2018, 9 , 4739 .

(11) (a) Ghosh, I.; Marzo, L.; Das, A.; Shaikh, R.; König, B. Visible Light Mediated Photoredox Catalytic Arylation Reactions. Acc. Chem. Res. 2016, 49, 1566-1577. (b) Nguyen, J. D.; D’Amato, E. M.; Narayanam, J. M. R.; Stephenson, C. R. J. Engaging unactivated alkyl, alkenyl and aryl iodides in visible-light-mediated free radical reactions. Nat. Chem. 2012, 4, 854-859. (c) Ghosh, I.; Ghosh, T.; Bardagi, J. I.; König, B. Reduction of aryl halides by consecutive visible light-induced electron transfer processes. Science 2014, 346 , 725-728. (d) Kim, H.; Lee, C. Visible-Light-Induced Photocatalytic Reductive Transformations of Organohalides. Angew. Chem. Int. Ed. 2012, 51, 12303-12306. (e) Cheng, Y.; Gu, X.; Li, P. Visible-Light Photoredox in Homolytic Aromatic Substitution: Direct Arylation of Arenes with Aryl Halides. Org. Lett. 2013, 15, 2664-2667.

(12) (a) Senaweera, S. M.; Singh, A.; Weaver, J. D. Photocatalytic Hydrodefluorination: Facile Access to Partially Fluorinated Aromatics. J. Am. Chem. Soc. 2014, 136, 3002-3005. (b) Senaweera, S.; Weaver, J. D. Dual C-F, C-H Functionalization via Photocatalysis: Access to Multifluorinated Biaryls. J. Am. Chem. Soc. 2016, 138, 2520-2523. (c) Singh, A.; Kubik, J. J.; Weaver, J. D. Photocatalytic C-F alkylation; facile access to multifluorinated arenes. Chem. Sci. 2015, 6, 7206-7212. (d) Singh, A.; Fennell, C. J.; Weaver, J. D. Photocatalyst size controls electron and energy transfer: selectable E/Z isomer synthesis via $\mathrm{C}-\mathrm{F}$ alkenylation. Chem. Sci. 2016, 7, 67966802. (e) Xie, J.; Rudolph, M.; Rominger, F.; Hashmi, S. K. Photoredox-Controlled Mono- and Di-Multifluoroarylation of $\mathrm{C}\left(\mathrm{sp}^{3}\right)-\mathrm{H}$ Bonds with Aryl Fluorides. Angew. Chem. Int. Ed. 2017, 56, 72667270. (f) Khaled, M. B.; El Mokadem, R. K.; Weaver, J. D. Hydrogen Bond Directed Photocatalytic Hydrodefluorination: Overcoming Electronic Control. J. Am. Chem. Soc. 2017, 139, 13092-13101. (g) Arora, A.; Weaver, J. D. Visible Light Photocatalysis for the Generation and Use of Reactive Azolyl and Polyfluoroaryl Intermediates. Acc. Chem. Res. 2016, 49, 2273-2283. (h) Xie, J.; Yu, J.; Rudolph, M.; Rominger, F.; Hashmi, S. K. Monofluoroalkenylation of Dimethylamino Compounds through Radical-Radical Cross-Coupling. Angew. Chem. Int. Ed. 2016, 55, 9416-9421.

(13) (a) Dombrowski, G.W.; Dinnocenzo, J. P.; Zielinski, P. A.; Farid, S.; Wosinska, Z. M.; Gould, I. R. Efficient Unimolecular Deprotonation of Aniline Radical Cations. J. Org. Chem. 2005, 70, 
3791-3800. (b) Hu, J.; Wang, J.; Nguyen, T. H.; Zheng, N. The chemistry of amine radical cations produced by visible light photoredox catalysis. Beilstein J. Org. Chem. 2013, 9, 1977-2001. (c) For $p K_{a}$ of DIPEA $^{\bullet+}$ please see: Beatty, J. W.; Stephenson, C. R. J. Amine Functionalization via Oxidative Photoredox Catalysis: Methodology Development and Complex Molecule Synthesis. Acc. Chem. Res. 2015, $48,1474-1484$.

(14) When 1b was used as substrate, we observed substantial amount of aryl iodide homo-coupling product and small amount of $\mathbf{1 b}$ homo-coupling product. To be specific, for $p$-methyl (4a), $m$-methyl (4b) and $p$-ethyl (4c) iodobenzenes, we isolated an inseparable mixture of both homo-coupling products (combined mass: for $\mathbf{4 a}-4.2$ $\mathrm{mg}$, for $\mathbf{4 b}-4.0 \mathrm{mg}$, for $\mathbf{4 c}-5.5 \mathrm{mg}$ ).

(15) Gutierezz, O.; Tellis, J. C.; Primer, D. N.; Molander, G. A.; Kozlowski, M. C. Nickel-Catalyzed Cross-Coupling of PhotoredoxGenerated Radicals: Uncovering a General Manifold for Stereoconvergence in Nickel-Catalyzed Cross-Couplings. J. Am. Chem. Soc. 2015, 137, 4896-4899.

(16) (a) Pischel, U.; Zhang, X.; Hellrung, B.; Haselbach, E.; Muller, P.-A.; Nau, W. M. Fluorescence Quenching of $n, \pi^{*}$-Excited
Azoalkanes by Amines: What Is a Sterically Hindered Amine?. J. Am. Chem. Soc. 2000, 122, 2027-2034. (b) Slinker, J. D.; Gorodetsky, A. A.; Lowry, M. S.; Wang, J.; Parker, S.; Rohl, R.; Bernhard, S.; Malliaras, G. G. Efficient Yellow Electroluminescence from a Single Layer of a Cyclometalated Iridium Complex. J. Am. Chem. Soc. 2004, 126, 2763-2767.

(17) For mechanistic investigations of Ni-catalyzed cross couplings with alkyl halides, see: (a) Biswas, S.; Weix, D. J. Mechanism and Selectivity in Nickel-Catalyzed Cross-Electrophile Coupling of Aryl Halides with Alkyl Halides. J. Am. Chem. Soc. 2013, 135, 16192-16197. (b) Schley, N. D.; Fu, G. C. Nickel-Catalyzed Negishi Arylations of Propargylic Bromides: A Mechanistic Investigation. $J$. Am. Chem. Soc. 2014, 136, 16588-16593. (c) Jones, G. D.; Martin, J.; McFarland, C.; Allen, O.; Hall, R.; Haley, A.; Brandon, R.; Konovalova, T.; Desrochers, P.; Pulay, P.; Vicic, D. Ligand Redox Effects in the Synthesis, Electronic Structure, and Reactivity of an Alkyl-Alkyl Cross-Coupling Catalyst. J. Am. Chem. Soc. 2006, 128, 13175-13183. 